\title{
ANALYSIS OF VOLUMETRIC SWELLING AND SHRINKAGE OF HEAT TREATED WOODS: EXPERIMENTAL AND ARTIFICIAL NEURAL NETWORK MODELING APPROACH
}

\author{
Sebahattin Tiryaki ${ }^{1, \diamond}$, Selahattin Bardak², Aytaç Aydın', Gökay Nemli ${ }^{1}$
}

\begin{abstract}
Shrinkage and swelling characteristics of wood as a hygroscopic material affect negatively its effective utilization for a variety of applications. Heat treatment is widely used for minimizing the negative effects of volumetric swelling and shrinkage of wood. The present study aims to develop artificial neural network (ANN) models for predicting volumetric swelling and shrinkage of heat treated woods. For this purpose, wood samples were subjected to heat treatment at varying temperatures $\left(130,150,170\right.$ and $\left.190{ }^{\circ} \mathrm{C}\right)$ for varying durations $(2,4,6$ and $8 \mathrm{~h})$. Experimental results have showed that volumetric swelling and shrinkage of wood decreased by heat treatment. Then, neural networks models capable of predicting the swelling and shrinkage of the treated woods were developed based on the resulting data. It was seen that ANN models allowed volumetric swelling and shrinkage of such woods to predict successfully with a limited set of experimental data. This approach was able to predict volumetric swelling and shrinkage of wood with a mean absolute percentage error equal to $2,599 \%$ and $2,647 \%$ in test phase, respectively. The developed models might thus serve as a robust tool to predict volumetric swelling and shrinkage with less number of experiments.
\end{abstract}

Keywords: Dimensional stability, heat treatment, hygroscopicity, neural network, swelling, wood properties.

\section{INTRODUCTION}

For centuries, wood has been widely used as a building material due to its superior properties. When compared with other competitive materials, it offers following advantages: it is a versatile material; it is a naturally renewable resource; it exhibits highly good thermal insulation; it provides a high strength and elasticity despite its low weight; it presents an aesthetic appearance and it is environmentally friendly. Such many factors have made the wood more suitable and more usable as a building material. However, it is worthy to mention that wood suffers from an unfavorable property. It is a highly hygroscopic material, and hence it undergoes shape changes with the fluctuations in relative humidity of the surrounding air (Camille and Kmaid 2005, Gryc et al. 2007).

It is possible to say that hygroscopicity is one of the main distinguishing characteristics of wood. It can be defined as the ability of the wood to lose or gain moisture with a change in relative humidity. Wood swells or shrinks as a result of this natural process. It is important to specify that volumetric swelling or shrinkage occurs below the fiber saturation point where all of the water exists only within the cell wall (Hiziroglu 2004, Almeida and Hernández 2006). Changes in humidity below this point lead to some problems in the use of wood. For instance, the gluing problems take place because of the different dimensional changes of the glued parts (Eckelman 1998). Besides, deformations and crack formations arise depending on the development of internal stresses due to similar reasons (Rastislav

\footnotetext{
${ }^{1}$ Department of Forest Industry Engineering, Faculty of Forestry, Karadeniz Technical University, Trabzon, Turkey. ${ }^{2}$ Department of Industrial Engineering, Faculty of Engineering and Architecture, Sinop University, Sinop, Turkey. •Corresponding author: sebahattintiryaki@hotmail.com Received: 31.08.2015 Accepted: 05.05.2016
} 
2006). Such drawbacks adversely affect the use of wood as a building material. On the other hand, these problems can be partially reduced if the wood is dried to the moisture content compatible with its final service environment (Hiziroglu 2004, Eckelman 1998). However, as mentioned previously, wood is easily affected by the changes in humidity of the surrounding air. Hence, it can be said that a more efficient solution is to reduce the hygroscopicity of wood.

Heat treatment is an effective procedure that aims at improving some wood properties (Unsal et al. 2003, Bal 2015). Heating the wood at high temperatures increases dimensional stability and biological durability and decreases hygroscopicity (Gunduz et al. 2008, Baysal et al. 2014). This fact is mainly related to the loss of the hemicellulose, which contributes greatly to water uptake due to its hydrophilic nature (Paul et al. 2007). In particular, the hydroxyl groups existing in hemicelluloses have a major impact on the volumetric swelling and shrinkage. Heat treatment provides a reduction in the number of these groups and thus wood absorbs less water (Inoue et al. 1993). As a result, the treated wood becomes less hydroscopic and more dimensionally stable compared to untreated wood (Shi et al. 2007, Korkut and Aytin 2015).

In light of the above observations, it is possible to say that swelling and shrinkage are important properties that have serious effects on the service life of wood products. It may be also said that heat treatment is a method that refers widely to reduce the negative effects of volumetric swelling and shrinkage. In the existing literature, many experimental studies for better understanding the impact of heat treatment on the amount of volumetric shrinkage and swelling of wood have been conducted so far (Esteves et al. 2007, Gunduz et al. 2008, Korkut and Budakci 2010). These studies have revealed that a large number of temperature and time values have to be investigated to detect a change in the swelling and shrinkage behavior of wood because of heat treatment. However, exhaustive tests bring about high costs and loss of time which are not preferable from industrial viewpoint. Recently, artificial neural networks (ANNs) have attracted attention of researchers as a new method in predicting various properties of materials. ANNs offer effective solutions to deal with complex problems and to uncover unknown relationship between input and output variables (Haghbakhsh et al. 2013). ANNs run based on learning and, when the established network is trained using an adequate number of data related to the problem, a new input that has a similar pattern can be predicted based on the previous learning pattern (Avunduk et al. 2014). As a result, the desired values regarding the problem in hand can be provided by carrying out less experimental studies. Due to such advantages, many researchers have focused on developing the ANN models for solving various problems of wood and wood products. Avramidis and Iliadis (2005), Zhang et al. (2006), Ceylan (2008), Rojas and Ortiz (2010), Esteban et al. (2011), Ozsahin (2012), Ozsahin (2013), Tiryaki and Aydin (2014), Tiryaki et al. (2014), Okan et al. (2015) and Bardak et al. (2016) are some of the studies carried out on ANN modeling in wood science.

Although there are above attempts regarding the use of ANN approach for solving various problems in wood science, very little information is available on predicting the swelling and shrinkage of wood species subjected to heat treatment. Hence, the present study has focused on developing ANN models that are capable of predicting the amount of volumetric swelling and shrinkage of heat treated woods. In this respect, this study will be the first attempt to model the volumetric swelling and shrinkage of wood based on wood species, treatment temperature, and exposure time using ANNs.

\section{Artificial neural networks (ANNS)}

ANNs are information processing tools that try to imitate the function of the human brain to perform efficiently a spesific task (Haykin 1999). They have the ability to reveal the complex relationships between input and outputs data in any system (Haykin 2008). Among many different kinds of ANNs, the multi-layer perceptron (MLP) is known as the most useful type. It is a feed-forward architecture that is capable of mapping the set of input data onto a set of proper outputs (Haghbakhsh et al. 2013). The MLP architecture comprises a combination of input, hidden and output layers. The input layer receives the data regarding the problem under consideration, the hidden layer processes the received data, and the output layer presents the response of the network to outside world (Zhang et al. 1998). Figure 1 displays a simple MLP architecture. In the case of MLP, the output is calculated as shown in Eq. (1) (Tiryaki and Hamzacebi 2014). 


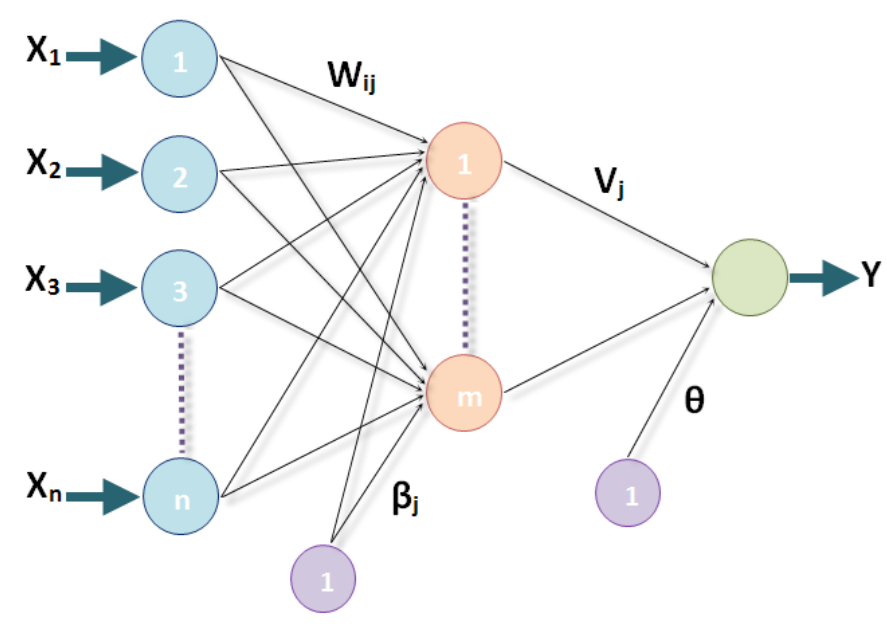

Figure 1. An example of MLP network.

$$
\mathrm{Y}=\mathrm{g}\left(\theta+\sum_{\mathrm{j}=1}^{\mathrm{m}} \mathrm{v}_{\mathrm{j}}\left[\sum_{\mathrm{i}=1}^{\mathrm{n}} \mathrm{f}\left(\mathrm{w}_{\mathrm{ij}} \mathrm{X}_{\mathrm{i}}+{ }^{2}{ }_{\mathrm{j}}\right)\right]\right)
$$

In Eq. (1), $Y$ is the predicted value of dependent variable; $X_{i}$ is the input value of $i^{\text {th }}$ independent variable; $w_{i j}$ is the connection weight between the $i^{\text {th }}$ input neuron and $j^{\text {th }}$ hidden neuron; $\beta \mathrm{j}$ is the value of the bias of the $\mathrm{j}^{\text {th }}$ hidden neuron; $\theta$ is the value of the bias of output neuron; $\mathrm{v}_{\mathrm{j}}$ is the connection weight between the $\mathrm{j}^{\text {th }}$ hidden neuron and output neuron; $\mathrm{g}($.$) and \mathrm{f}($.$) are the activation functions for$ hidden and output layers, respectively.

The basic element of ANNs is the neurons. They are connected to each other by a weight factor analogously to the biological nervous system (Zhang et al. 1998). The main task of the connection weights is to store the information and reveal the relationship between input and output data (Haghbakhsh et al. 2013).

To reveal the complex relationships among data, a neural network does not require a preliminary knowledge regarding the problem under consideration. Instead of this, it learns through the samples to capture this relationship. A successful ANN model is created by three main phases, which are known as training, validation and testing. For this purpose, the existing data are generally divided into three subsets (Zhang et al. 1998, Avunduk et al. 2014). In the first stage, the network is trained using the training data. During the training, random numbers are designated to the weight corresponding to each input variables. The second phase is known as the validation phase. This phase is carried out to generalize the established network (Hagan et al. 2002). The last phase is the testing phase that resembles the validation phase except in one difference. The validation phase is considered as a criterion to end the training phase, while testing phase is performed to measure the performance of the trained and validated network (Hagan et al. 2002, Avunduk et al. 2014). Thus, it is possible to properly evaluate the performance of the established model (May et al. 2010). 


\section{MATERIALS AND METHODS}

\section{Materials}

Experimental materials chosen for this study were beech wood (Fagus orientalis Lipsky.) with a density of $660 \mathrm{~kg} / \mathrm{m}^{3}$ and pine wood (Pinus slyvestris Lipsky.) with a density of $520 \mathrm{~kg} / \mathrm{m}^{3}$. The samples for the experiments were all randomly selected from Artvin, Turkey. Special emphasis was paid to the selection of them without any defects. Thus, the experiments were performed using flawless samples.

\section{Heat treatment application}

Experimental samples were subjected to heat treatment at different temperatures $\left(130{ }^{\circ} \mathrm{C}, 150{ }^{\circ} \mathrm{C}\right.$, $170^{\circ} \mathrm{C}$ and $\left.190^{\circ} \mathrm{C}\right)$ for different exposure times $(2 \mathrm{~h}, 4 \mathrm{~h}, 6 \mathrm{~h}$ and $8 \mathrm{~h})$. This operation was carried out using a heating oven controlled at an accuracy of $1{ }^{\circ} \mathrm{C}$ under atmospheric pressure. The samples were then conditioned to the moisture content of $12 \%$ at a temperature of $20 \pm 2{ }^{\circ} \mathrm{C}$ and a relative humidity of $65 \pm 5 \%$.

\section{Determination of weight loss}

Experimental samples were dried in a heating oven at a temperature of $103 \pm 2{ }^{\circ} \mathrm{C}$ prior to heat treatment. Oven-dry weights of the samples were then detected with $\pm 0,01 \mathrm{~g}$ sensitivity. Following the heat treatment, the weights of the same samples were measured again. Eq. (2) gives the weight loss of the samples because of heat treatment. The calculated values of the weight loss were presented in Table 1.

$$
\mathrm{W}(\%)=\frac{\left(\mathrm{m}_{\mathrm{b}}-\mathrm{m}_{\mathrm{a}}\right)}{\mathrm{m}_{\mathrm{b}}} \times 100
$$

In Eq. (2), $\mathrm{W}(\%)$ is the weight loss; $\mathrm{m}_{\mathrm{b}}$ is the oven-dry weight of the sample prior to treatment and $\mathrm{m}_{\mathrm{a}}$ is the oven-dry weight of the same sample after treatment.

\section{Swelling and shrinkage experiments}

It is well known that wood changes its dimensions in three different directions: tangential, radial and longitudinal. Most researchers reported that the dimensional change (swelling or shrinkage) in the longitudinal direction is negligible (Usta and Guray 2000, Gryc et al. 2007). We, therefore, calculated the dimensional change in tangential and radial diections of the samples subjected to heat treatment. For this purpose, experimental samples of swelling and shrinkage were prepared with dimensions of $30 \times 30 \times 15 \mathrm{~mm}$. For the swelling, the air-dry samples were dried in a drying cabinet at the temperature of $103 \pm 2{ }^{\circ} \mathrm{C}$. Then, the tangential and radial dimensions were measured. After this process, the samples were kept in water for one week until they became completely saturated. The dimensions were next measured again. The amount of the swelling in both tangential $\left(\alpha_{\mathrm{t}}\right)$ and radial $\left(\alpha_{\mathrm{r}}\right)$ directions was calculated by Eq. (3). The total volumetric swelling $\left(\alpha_{\mathrm{v}}\right)$ was obtained by the sum of the amount of swelling in both directions. Swelling experiments were carried out based on the procedure of TS 4084 (1983) standard.

$$
\alpha(\%)=\frac{\left(\mathrm{D}_{\mathrm{s}}-\mathrm{D}_{\mathrm{o}}\right)}{\mathrm{D}_{\mathrm{o}}} \times 100
$$


To calculate the volumetric shrinkage of the samples, air-dry samples were firstly kept in water for one week, and then the tangential and radial dimensions of them were measured with $\pm 0,1 \mathrm{~mm}$ sensitivity. The same samples were next dried in the drying cabinet at the temperature of $103 \pm 2$ ${ }^{\circ} \mathrm{C}$. After drying, the sample dimensions were measured again. The amount of the shrinkage in both tangential $\left(\beta_{\mathrm{t}}\right)$ and radial $\left(\beta_{\mathrm{r}}\right)$ directions was calculated using Eq. (4). The total volumetric shrinkage $\left(\beta_{\mathrm{v}}\right)$ was obtained by the sum of the amount of shrinkage in both directions. Shrinkage experiments were carried out based on the procedure of TS 4083 (1983) standard.

$$
\beta(\%)=\frac{\left(D_{s}-D_{o}\right)}{D_{s}} \times 100
$$

In Eqs. (3) and (4); $\alpha$ is the amount of the swelling as a percentage, $\beta$ is the amount of the shrinkage as a percentage, $\mathrm{D}_{\mathrm{s}}$ is the dimension in the saturated state of the sample $(\mathrm{mm})$ and $\mathrm{D}_{\mathrm{o}}$ is the oven-dry dimension of the sample $(\mathrm{mm})$.

\section{Application of ANNs for predicting volumetric swelling and shrinkage}

\section{Data collection and preparation}

In this study, the change in the volumetric swelling and shrinkage based on wood species, treatment temperature and exposure time was predicted by the ANN models developed in the MATLAB software package. The volumetric swelling and shrinkage data used in the present modeling study were collected by carrying out a series of experiments. A total of thirty-two data were used for each of volumetric swelling and shrinkage.

An important step of model building process is data division. At this stage, the existing data are generally divided into training, validation and testing sets (Zhang et al. 1998). Hence, the experimental data of volumetric swelling and shrinkage were randomly divided to three data sets (data sets see Table 1). Each network was trained with twenty two data ( $70 \%$ of total data) and was subsequently validated with five experimental data ( $15 \%$ of total data) and tested with five experimental data (15\% of total data). It is worth mentioning that each data corresponds to the average of 30 measurements. The volumetric swelling $\left(\alpha_{v}\right)$ and volumetric shrinkage $\left(\beta_{v}\right)$ data were used in the models, and they were given in Table 1.

\section{Model architectures}

Any ANN architecture is formed by the combination of the layers and their neurons (Zhang et al. 1998). In the present study, the optimal architectures of ANN models for both volumetric swelling and shrinkage include one input layer, one hidden layer and one output layer. The optimal architectures mean the best explanation of the relationship between input and output data. Figure 2 shows the representations of the optimal architectures of the ANN models for predicting volumetric swelling and shrinkage of heat treated pine and beech. 


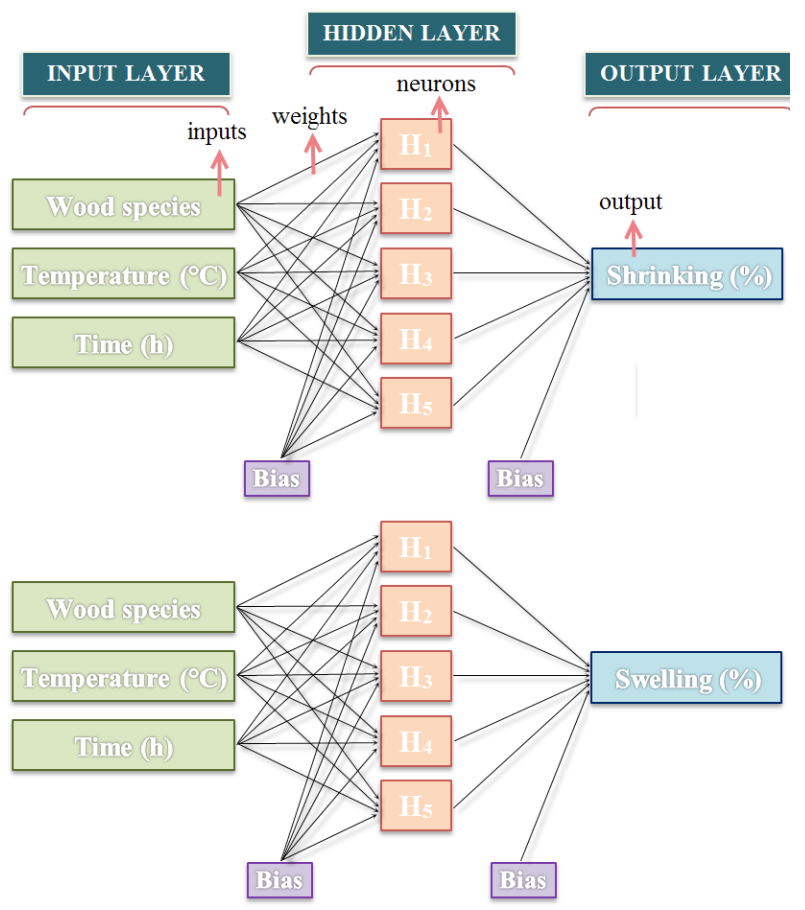

Figure 2. Network architectures for models.

Regarding the neurons of layers, it was previously reported that the number of input and output neurons corresponds to the number of input and output variables, respectively (Tiryaki and Hamzacebi 2014). Hence, the inputs of both models for the present study were wood species, treatment temperature and exposure time, while the outputs of the models were volumetric swelling and shrinkage.

It is important to state that the hidden layer and hidden neurons are highly important in terms of the success of ANN applications since they allow the networks to capture complex relationship between input and output data (Zhang et al. 1998). In this study, an important goal was thus to find the optimum number of hidden layers and hidden neurons of both models. Zhang et al. (1998) says that the most frequently used procedure in detecting the optimal number of them is a trial and error process. This study therefore used the trial and error method to achieve this goal. For each ANN, various network configurations were tried until the best network configurations for swelling and shrinkage were found. As a result, as seen in Figure 2, the best performance of the ANN models for both swelling and shrinkage was provided for one hidden layer and five hidden neurons. 


\section{Performance evaluation of models}

Predictive ability of the established models was evaluated by performance indicators such as the mean absolute percentage error (MAPE), the root mean square error (RMSE) and determination coefficient $\left(\mathrm{R}^{2}\right)$. The MAPE and RMSE were used to calculate the error levels of the models, while $\mathrm{R}^{2}$ was used to determine the relationship or the similarity between experimental and model outputs. The values of them were mathematically calculated with Eq. (5) - (6) - (7).

$$
\begin{aligned}
& \text { MAPE }=\frac{1}{N}\left(\sum_{i=1}^{N}\left[\left|\frac{t_{i}-t_{i}}{t_{i}}\right|\right]\right) \times 100 \\
& \text { RMSE }=\sqrt{\frac{1}{N} \sum_{i=1}^{N}\left(t_{i}-t_{i}\right)^{2}} \\
& R^{2}=1-\frac{\sum_{i=1}^{N}\left(t_{i}-t_{i}\right)^{2}}{\sum_{i=1}^{N}\left(t_{i}-\bar{t}\right)^{2}}
\end{aligned}
$$

Where, $t_{i}$ represents the experimental output, $\mathrm{td}_{\mathrm{i}}$ represents the predicted output, $\mathrm{N}$ represents the total number of samples and $\bar{t}$ represents the mean of predicted outputs.

\section{RESULTS AND DISCUSSION}

\section{Experimental results}

Table 1 displays the mean values of swelling, shrinkage and weight loss of pine and beech samples subjected to different temperatures and durations of heat treatment. 
Table 1. Experimental values of swelling and shrinkage and weight loss of treated samples.

\begin{tabular}{|c|c|c|c|c|c|c|c|c|c|c|}
\hline \multirow[b]{2}{*}{$\begin{array}{l}\text { Wood } \\
\text { species }\end{array}$} & \multirow[b]{2}{*}{$\begin{array}{c}\text { Temperature } \\
\left({ }^{\circ} \mathrm{C}\right)\end{array}$} & \multirow[b]{2}{*}{$\begin{array}{l}\text { Time } \\
\text { (h) }\end{array}$} & \multirow[b]{2}{*}{$\mathrm{N}$} & \multicolumn{3}{|c|}{ Swelling (\%) } & \multicolumn{3}{|c|}{ Shrinkage (\%) } & \multirow{2}{*}{$\begin{array}{c}\text { Weight } \\
\text { Loss } \\
(\%)\end{array}$} \\
\hline & & & & $\alpha_{t}$ & $\alpha_{\mathrm{r}}$ & $\alpha_{\mathrm{v}}$ & $\beta_{t}$ & $\beta_{\mathrm{r}}$ & $\beta_{\mathrm{v}}$ & \\
\hline Pine & 130 & 2 & 60 & 8,418 & 4,268 & 12,686 & 7,990 & 4,102 & 12,092 & 0,390 \\
\hline Pine & 130 & 4 & 60 & 7,830 & 4,124 & 11,954 & 7,494 & 3,888 & 11,382 & 0,582 \\
\hline Pine & 130 & 6 & 60 & 7,460 & 3,986 & 11,446 & 7,144 & 3,756 & 10,900 & 0,628 \\
\hline Pine & 130 & 8 & 60 & 7,206 & 3,842 & 11,048 & 6,990 & 3,578 & 10,568 & 0,714 \\
\hline Pine & 150 & 2 & 60 & 7,308 & 4,026 & 11,334 & 7,042 & 3,636 & 10,678 & 0,670 \\
\hline Pine & 150 & 4 & 60 & 6,854 & 3,812 & 10,666 & 6,836 & 3,306 & 10,142 & 0,768 \\
\hline Pine & 150 & 6 & 60 & 6,376 & 3,502 & 9,878 & 6,340 & 3,072 & 9,412 & 0,908 \\
\hline Pine & 150 & 8 & 60 & 6,054 & 3,224 & 9,278 & 5,488 & 2,768 & 8,256 & 1,176 \\
\hline Pine & 170 & 2 & 60 & 6,118 & 3,332 & 9,450 & 5,526 & 2,666 & 8,192 & 1,074 \\
\hline Pine & 170 & 4 & 60 & 5,660 & 3,144 & 8,804 & 5,164 & 2,456 & 7,620 & 1,468 \\
\hline Pine & 170 & 6 & 60 & 5,182 & 3,078 & 8,260 & 4,866 & 2,280 & 7,146 & 1,838 \\
\hline Pine & 170 & 8 & 60 & 4,594 & 2,986 & 7,580 & 4,282 & 2,160 & 6,442 & 2,514 \\
\hline Pine & 190 & 2 & 60 & 4,240 & 2,782 & 7,022 & 3,866 & 2,188 & 6,054 & 3,806 \\
\hline Pine & 190 & 4 & 60 & 3,676 & 2,024 & 5,700 & 3,146 & 1,910 & 5,056 & 4,878 \\
\hline Pine & 190 & 6 & 60 & 3,342 & 1,808 & 5,150 & 2,618 & 1,542 & 4,160 & 5,342 \\
\hline Pine & 190 & 8 & 60 & 2,902 & 1,468 & 4,370 & 2,634 & 1,210 & 3,844 & 6,380 \\
\hline Beech & 130 & 2 & 60 & 13,908 & 5,058 & 18,966 & 11,216 & 5,300 & 16,516 & 0,318 \\
\hline Beech & 130 & 4 & 60 & 13,746 & 4,986 & 18,732 & 11,160 & 5,212 & 16,372 & 0,522 \\
\hline Beech & 130 & 6 & 60 & 13,416 & 4,598 & 18,014 & 11,148 & 5,174 & 16,322 & 0,606 \\
\hline Beech & 130 & 8 & 60 & 13,162 & 4,388 & 17,550 & 10,854 & 4,842 & 15,696 & 1,264 \\
\hline Beech & 150 & 2 & 60 & 13,446 & 4,648 & 18,094 & 11,138 & 5,224 & 16,362 & 1,182 \\
\hline Beech & 150 & 4 & 60 & 13,190 & 4,396 & 17,586 & 10,816 & 4,910 & 15,726 & 1,414 \\
\hline Beech & 150 & 6 & 60 & 12,956 & 4,078 & 17,034 & 10,524 & 4,590 & 15,114 & 1,736 \\
\hline Beech & 150 & 8 & 60 & 12,482 & 3,764 & 16,246 & 10,150 & 4,282 & 14,432 & 1,892 \\
\hline Beech & 170 & 2 & 60 & 12,506 & 3,826 & 16,332 & 10,172 & 4,290 & 14,462 & 1,834 \\
\hline Beech & 170 & 4 & 60 & 11,690 & 3,722 & 15,412 & 9,888 & 4,060 & 13,948 & 2,182 \\
\hline Beech & 170 & 6 & 60 & 10,976 & 3,474 & 14,450 & 9,468 & 3,754 & 13,222 & 2,442 \\
\hline Beech & 170 & 8 & 60 & 10,546 & 3,426 & 13,972 & 9,118 & 3,556 & 12,674 & 2,886 \\
\hline Beech & 190 & 2 & 60 & 10,520 & 3,494 & 14,014 & 9,000 & 3,512 & 12,512 & 4,064 \\
\hline Beech & 190 & 4 & 60 & 9,904 & 3,146 & 13,050 & 8,234 & 3,260 & 11,494 & 5,172 \\
\hline Beech & 190 & 6 & 60 & 9,084 & 2,986 & 12,070 & 7,548 & 3,016 & 10,564 & 6,534 \\
\hline Beech & 190 & 8 & 60 & 8,036 & 2,808 & 10,844 & 6,964 & 2,770 & 9,734 & 7,662 \\
\hline
\end{tabular}

The effects of wood species, treatment temperature and exposure time on the amount of volumetric swelling and shrinkage of the samples were statistically evaluated by analysis of variance (ANOVA). From the ANOVA results, it was understood that the effects of all the variables analyzed on the volumetric swelling and shrinkage of the samples were highly significant at the $95 \%$ confidence level. In the following, significant differences between the groups were detected individually for swelling and shrinkage based on wood species, treatment temperature and exposure time by Duncan's multiple mean comparison test. The results of the Duncan test indicated that the mean values of volumetric swelling and shrinkage depending on treatment temperature and exposure time consist of four different groups, while wood species consists of two different groups. The results of Duncan's grouping are shown in Figure 3 by letters. 

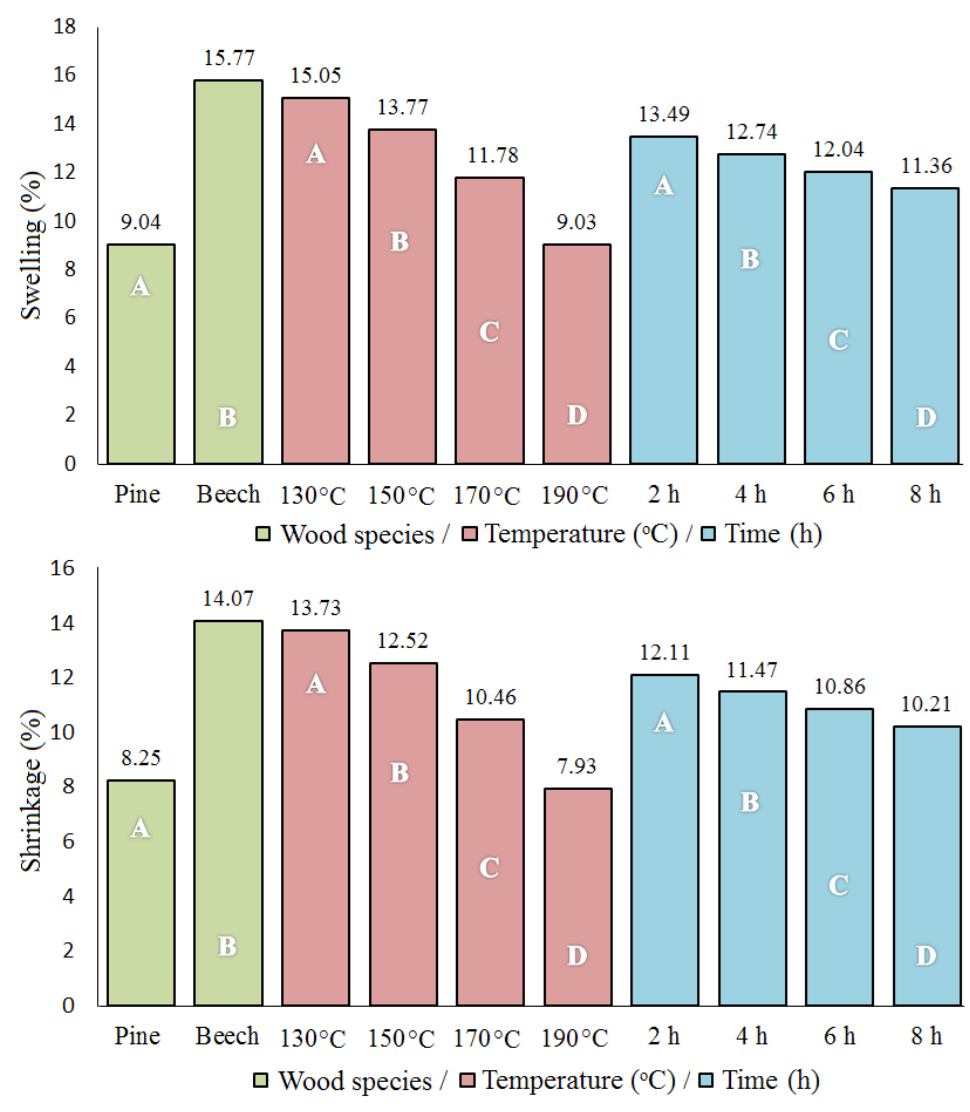

Figure 3. Mean values of volumetric swelling and volumetric shrinkage of experimental samples and the results of Duncan's multiple mean comparison test.

Once Table 1 and Figure 3 are together evaluated in terms of the wood species, it is possible to see that volumetric swelling and shrinkage values of beech are higher than that of pine. From the mean values in Figure 3, it can be seen that volumetric swelling and shrinkage of beech wood are $15,77 \%$ and $14,07 \%$; respectively, while corresponding values of pine wood are $9,04 \%$ abd $8,25 \%$ respectively. It can be therefore said that volumetric swelling and shrinkage was higher for beech wood compared to pine wood. The main reason behind this was reported as wood density (Guler et al. 2007). This opinion was supported by Kord et al. (2010). As found in the current study, it is well known that beech has a higher density than pine. 
For the influences of the temperature and time of heat treatment on volumetric swelling and shrinkage, it was observed that volumetric swelling and shrinkage significantly decreased in both tangential and radial directions with heat treatment. The reduction became greater with an increase in temperature and duration of heat treatment. In terms of the volumetric swelling, the greatest value was found to be $12,686 \%$ for pine samples and $18,966 \%$ for beech samples treated at $130{ }^{\circ} \mathrm{C}$ for $2 \mathrm{~h}$. With heat treatment applied at $190{ }^{\circ} \mathrm{C}$ for $8 \mathrm{~h}$, it was seen that the amount of volumetric swelling dropped to $4,370 \%$ for pine samples and $10,844 \%$ for beech samples. Corresponding values of volumetric shrinkage were observed as $12,092 \%$ for pine samples and $16,516 \%$ for beech samples treated at $130{ }^{\circ} \mathrm{C}$ for $2 \mathrm{~h}$. Similarly to volumetric swelling, volumetric shrinkage values dropped to $3,844 \%$ and $9,734 \%$ for pine and beech samples as a result of the heat treatment applied at $190{ }^{\circ} \mathrm{C}$ for $8 \mathrm{~h}$, respectively. In briefly, the findings of the present study revealed that heat treatment reduces considerably volumetric swelling and shrinkage. Similar findings were also reported by several previous researchers (Feist and Sell 1987, Esteves et al. 2007, Schneid et al. 2014, Bal 2015, Korkut and Aytin 2015). Stamm (1964) stated that this is mainly associated with the degradation of the hemicelluloses. Hemicelluloses degrade during heat treatment, and thus the number of their free hydroxyl groups reduces. The reduction of hydrophilic hydroxyl groups in wood leads to an increase in the proportion of lignin. This improves the hydrophobic behavior of the wood (de Moura et al. 2011). Wood thus absorbs less water (Inoue et al. 1993) and it swells and shrinks less compared to untreated wood (Shi et al. 2007).

For the present study, it is also important to state that swelling and shrinkage in tangential direction in wood were found higher compared to swelling and shrinkage in radial direction. Similar observations were also reported by Usta and Guray (2000) and Esteves et al. (2007). Usta and Guray (2000) says that this can be partly explained by the presence of the ray cells.

Based on the current study's findings, it is possible to say that heat treatment is a useful procedure to enhance the dimensional stability of wood, which is required for some applications. In earlier studies, many researchers reported that heat treated wood can be utilized for outdoor applications such as exterior cladding, garden furniture, window and door frames, due to the enhanced dimensional stability. Furthermore, such woods gives better durability for coating (Yildiz et al. 2006, Gunduz et al. 2008, Korkut and Budakci 2010). As a result of the improvoment of their dimensional stability, it can be said for the present study that heat treated pine and beech can be effectively utilized in areas where they had limited use before.

\section{Modeling results}

Table 2 shows the predicted values of the experimental samples of volumetric swelling and shrinkage by means of the ANN models and their percentage errors.

As seen in Table 2, the prediction of volumetric swelling and shrinkage of the samples was achieved with low percentage errors by the established ANN models. Namely, the ANN outputs were highly close to the experimental outputs in predicting both swelling and shrinkage. Among all variations, the maximum absolute percentage error was $4,718 \%$ for swelling and $7,673 \%$ for shrinkage, while the minimum absolute percentage error was $0,009 \%$ for swelling and $0,056 \%$ for shrinkage. As seen, the amount of the error varies between $7,673 \%$ and $0,009 \%$. Due to high degree of the similarity or closeness between the experimental outputs and predicted outputs, it is possible to say that the ANN predictions are highly good. 
Table 2. Predicted values of the experimental samples of volumetric swelling and shrinkage and their percentage errors.

\begin{tabular}{|c|c|c|c|c|c|c|c|}
\hline \multirow{2}{*}{$\begin{array}{c}\text { Wood } \\
\text { species }\end{array}$} & \multirow{2}{*}{ Temperature $\left({ }^{\circ} \mathrm{C}\right)$} & \multirow{2}{*}{ Time (h) } & \multirow{2}{*}{$\mathrm{N}$} & \multicolumn{2}{|c|}{ Swelling (\%) } & \multicolumn{2}{|c|}{ Shrinkage $(\%)$} \\
\hline & & & & Predicted & $\%$ Error & Predicted & $\%$ Error \\
\hline Pine & 130 & 2 & 60 & 12,669 & 0,134 & 11,909 & 1,513 \\
\hline Pine & 130 & 4 & 60 & 12,100 & $-1,221$ & 11,396 & $-0,123$ \\
\hline Pine & 130 & 6 & 60 & 11,408 & 0,332 & 10,930 & $-0,275$ \\
\hline Pine & 130 & 8 & 60 & 10,820 & 2,064 & 10,604 & $-0,341$ \\
\hline Pine & 150 & 2 & 60 & 11,346 & $-0,106$ & 10,672 & 0,056 \\
\hline Pine & 150 & 4 & 60 & 10,589 & 0,722 & 10,112 & 0,296 \\
\hline Pine & 150 & 6 & 60 & 9,953 & $-0,759$ & 9,3539 & 0,617 \\
\hline Pine & 150 & 8 & 60 & 9,347 & $-0,744$ & 8,370 & $-1,381$ \\
\hline Pine & 170 & 2 & 60 & 9,474 & $-0,254$ & 8,317 & $-1,526$ \\
\hline Pine & 170 & 4 & 60 & 8,776 & 0,318 & 7,775 & $-2,034$ \\
\hline Pine & 170 & 6 & 60 & 8,196 & 0,775 & 7,178 & $-0,448$ \\
\hline Pine & 170 & 8 & 60 & 7,566 & 0,185 & 6,453 & $-0,171$ \\
\hline Pine & 190 & 2 & 60 & 7,009 & 0,185 & 5,810 & 4,030 \\
\hline Pine & 190 & 4 & 60 & 5,729 & $-0,509$ & 5,019 & 0,732 \\
\hline Pine & 190 & 6 & 60 & 4,907 & 4,718 & 4,436 & $-6,635$ \\
\hline Pine & 190 & 8 & 60 & 4,367 & 0,069 & 3,991 & $-3,824$ \\
\hline Beech & 130 & 2 & 60 & 18,964 & 0,011 & 16,577 & $-0,369$ \\
\hline Beech & 130 & 4 & 60 & 18,558 & 0,929 & 16,340 & 0,195 \\
\hline Beech & 130 & 6 & 60 & 18,061 & $-0,261$ & 16,091 & 1,415 \\
\hline Beech & 130 & 8 & 60 & 17,493 & 0,325 & 15,852 & $-0,994$ \\
\hline Beech & 150 & 2 & 60 & 18,059 & 0,195 & 16,404 & $-0,257$ \\
\hline Beech & 150 & 4 & 60 & 17,619 & $-0,188$ & 15,757 & $-0,197$ \\
\hline Beech & 150 & 6 & 60 & 17,054 & $-0,117$ & 15,087 & 0,179 \\
\hline Beech & 150 & 8 & 60 & 16,289 & $-0,265$ & 14,498 & $-0,457$ \\
\hline Beech & 170 & 2 & 60 & 15,870 & 2,829 & 14,566 & $-0,719$ \\
\hline Beech & 170 & 4 & 60 & 15,402 & 0,065 & 14,020 & $-0,516$ \\
\hline Beech & 170 & 6 & 60 & 14,792 & $-2,367$ & 13,305 & $-0,628$ \\
\hline Beech & 170 & 8 & 60 & 13,984 & $-0,086$ & 12,688 & $-0,110$ \\
\hline Beech & 190 & 2 & 60 & 14,358 & $-2,455$ & 11,552 & 7,673 \\
\hline Beech & 190 & 4 & 60 & 13,261 & $-1,617$ & 10,969 & 4,568 \\
\hline Beech & 190 & 6 & 60 & 12,061 & 0,075 & 10,380 & 1,742 \\
\hline Beech & 190 & 8 & 60 & 10,845 & $-0,009$ & 9,790 & $-0,575$ \\
\hline
\end{tabular}

Note; bold values: testing data, bold italics values: validation data, the other values: training data

$\mathrm{N}$ : Number of samples

As mentioned previously, MAPE, RMSE and $\mathrm{R}^{2}$ were calculated to assess the prediction capability of the established networks. Table 3 gives evaluation results of the models in terms of the values of these criteria.

Table 3. Evaluation results of the criteria used in predicting volumetric swelling and shrinkage of the samples.

\begin{tabular}{|l|c|c|c|c|c|c|}
\hline \multirow{2}{*}{ Data sets } & \multicolumn{3}{|c|}{ Swelling (\%) } & \multicolumn{3}{c|}{ Shrinkage (\%) } \\
\cline { 2 - 7 } & RMSE & MAPE & $\mathrm{R}^{2}$ & RMSE & MAPE & $\mathrm{R}^{2}$ \\
\hline Training data & 0,046 & 0,278 & 0,9999 & 0,104 & 0,981 & 0,9995 \\
\hline Validation data & 0,100 & 1,153 & 0,9985 & 0,176 & 1,955 & 0,9974 \\
\hline Testing data & 0,308 & 2,599 & 0,9968 & 0,491 & 2,647 & 0,9847 \\
\hline
\end{tabular}

It is important to note that the ANN predictions are optimum if RMSE and MAPE are found to 
be close to 0 , while $\mathrm{R}^{2}$ are found to be close to 1 (Haghbakhsh et al. 2013). According to Table 3, the RMSE values for the test phase were determined as 0,308 and 0,491 in predicting volumetric swelling and shrinkage of samples, respectively. It can be thus said that the prediction of volumetric swelling and shrinkage was successful in terms of the RMSE criterion.

Among the evaluation criteria, the criterion of MAPE, which corresponds to the average of the errors in Table 2, is mostly accepted as the main criterion in making a decision on the performance of a model (Tiryaki and Hamzacebi 2014). The MAPE shows the average of the percentage deviation from the targeted value. It is obvious from Table 3 that MAPE values were found as $0,278 \% ; 1,153 \%$ and $2,599 \%$ in the prediction of volumetric swelling and $0,981 \% ; 1,955 \%$ and $2,647 \%$; in the prediction of volumetric shrinkage for training, validation and testing data sets, respectively. These low levels of the MAPE demonstrate that ANN approach effectively gives accurate outputs. Lewis (1982) reported that predictive ability of a model is considered as perfect if its MAPE value is below $10 \%$. Accordingly, the prediction ability of the models for swelling and shrinkage is perfect with MAPE values of 2,599\% and 2,647\% respectively. According to Bas and Boyaci (2007), evaluation of $\mathrm{R}^{2}$ and MAPE together is useful to check the validity of a model.

In addition to the criterion of the MAPE, the performance of the models was analyzed based on the $\mathrm{R}^{2}$ between the model predictions and the experimental outputs. $\mathrm{R}^{2}$ is a statistical measure of the relationship between actual and predicted outputs (Taylor 1990). As referred above, this value should be as close to 1 as possible for a successful prediction. Figure 4 and Figure 5 show the plot of the experimental outputs versus the model outputs of volumetric swelling and shrinkage of the samples for data sets.

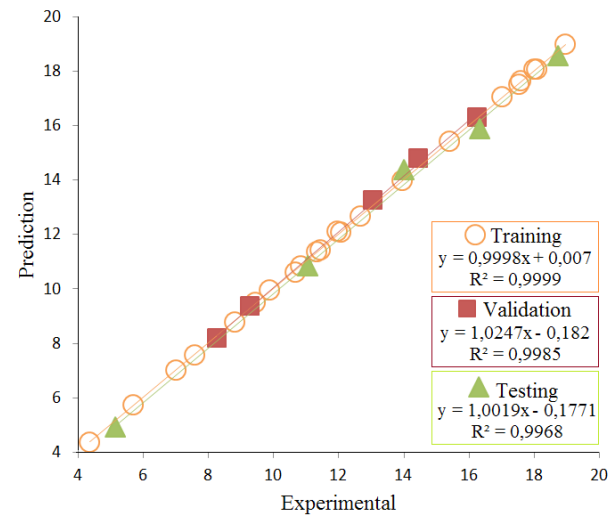

Figure 4. Relationship between the experimental outputs and model outputs of volumetric swelling for data sets.

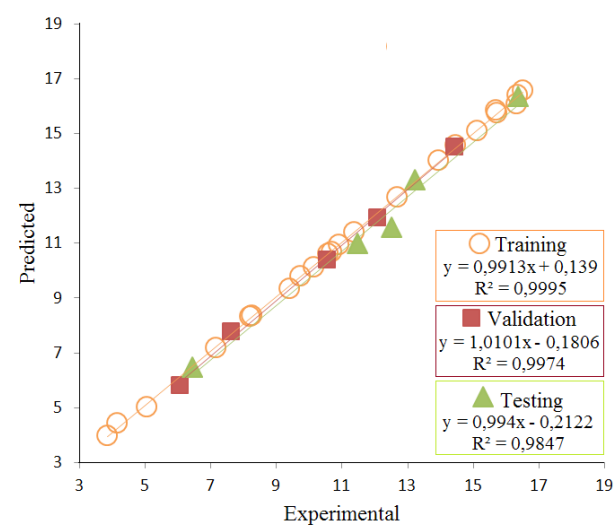

Figure 5. Relationship between the experimental outputs and model outputs of volumetric shrinkage for data sets. 
From the plots given in Figure 4 and Figure 5, it can be clearly observed that the $\mathrm{R}^{2}$ values were found as 0,$9999 ; 0,9985$ and 0,9968 in the prediction of volumetric swelling and 0,$9995 ; 0,9974$ and 0,9847 in the prediction of volumetric shrinkage for training, validation and testing data sets, respectively. These findings mean that the models are capable of explaining at least $99 \%$ of the experimental outputs of volumetric swelling and $98 \%$ of the experimental outputs of volumetric shrinkage in the testing phase. Hence, it is possible to say that the proposed networks have a high explanatory. In brief, the high values of $\mathrm{R}^{2}$ and the low values of the error terms such as MAPE and RMSE in testing set have demonstrated that the ANN approach is highly convenient to model the volumetric swelling and shrinkage of heat treated woods. In other words, ANNs have been proved as a robust tool for predicting volumetric swelling and shrinkage of the wood subjected to heat treatment without carrying out the more empirical investigation requiring much time and high experimental costs.

On the other hand, as stated before, very limited information is available on predicting volumetric swelling and shrinkage of solid wood subjected to the heat treatment using the ANN approach. Only, several attempts were made to predict the thickness swelling of wood based composites. For instance, Ozsahin (2012) and (2013) used the ANN technique to predict the thickness swelling of oriented strand board. These studies have revealed that ANN could be effectively used to model the thickness swelling of oriented strand board. Similarly, the present modeling study was highly successful in predicting the volumetric swelling and shrinkage of pine and beech woods exposed to heat treatment.

\section{CONCLUSIONS}

This study has focused on modeling the effects of treatment temperature and exposure time on volumetric swelling and shrinkage of heat treated beech and pine woods by means of the ANNs. The data for modeling study were provided by swelling and shrinkage experiments.

Experimental results have showed that heat treatment significantly reduced the amount of volumetric swelling and shrinkage of wood in both radial and tangential directions. This might present a major advantage for reducing the problems caused by swelling and shrinkage in wood.

The higher treatment temperature and longer heating duration provided lower swelling and shrinkage. In other words, heat treated wood was more dimensionally stable when it was exposed to high temperature compared with exposure to low temperature.

The findings of this study contribute to a better understanding of volumetric swelling and shrinkage behaviors of treated woods. This will help to perform more effectively the applications such as coating, gluing and finishing.

The outputs of the ANN models were found to be agreed with experimental outputs. The models were able to predict the amount of volumetric swelling and shrinkage of woods subjected to heat treatment with an acceptable accuracy.

Thus, it is feasible to say that the well trained ANN models can be considered to predict the amount of volumetric swelling and shrinkage of heat treated woods. As a result, reasonable results can be predicted by the ANN instead of carrying out the time consuming and costly experimental investigation.

It is worthy to mention that the prediction of volumetric swelling and shrinkage of the treated wood by ANNs may be considered as an alternative approach for practitioners in the wood industry to ensure the success of the applications such as coating and finishing. 


\section{REFERENCES}

Almeida, G.; Hernandez, R.E. 2006. Changes in physical properties of tropical and temperate hardwoods below and above the fiber saturation point. Wood Science and Technology 40:599-613.

Avramidis, S.; Iliadis, L. 2005. Predicting wood thermal conductivity using artificial neural networks. Wood and Fiber Science 37:682-690.

Avunduk, E.; Tumac, D.; Atalay, A.K. 2014. Prediction of roadheader performance by artificial neural network. Tunnelling and Underground Space Technology 44:3-9.

Bal, B.C. 2015. Physical properties of beech wood thermally modified in hot oil and in hot air at various temperatures. Maderas. Ciencia y tecnología 17(4):789-798.

Bardak, S.; Tiryaki, S.; Nemli, G.; Aydin, A. 2016. Investigation and neural network prediction of wood bonding quality based on pressing conditions. International Journal of Adhesion and Adhesives 68:115-123.

Bas, D.; Boyaci, I.H. 2007. Modeling and optimization I: Usability of response surface methodology. Journal of Food Engineering 78:836-845.

Baysal, E.; Kart, S.; Toker H.; Degirmentepe, S. 2014. Some physical characteristics of thermally modified Oriental-beech wood. Maderas. Ciencia y tecnología 16(3):291-298.

Camille, A.I.; Kmeid, Z. 2005. Advanced wood engineering: glulam beams. Construction and Building Materials 19:99-106.

Ceylan, I. 2008. Determination of drying characteristics of timber by using artificial neural networks and mathematical models. Drying Technology 26:1469-1476.

de Moura, L.F.; Brito, J.O.; Nolasco, A.M.; Uliana, L.R. 2011. Effect of thermal rectification on machinability of Eucalyptus grandis and Pinus caribaea var. hondurensis woods. European Journal of Wood and Wood Products 69:641-648.

Eckelman, C. 1998. The shrinking and swelling of wood and its effect on furniture. FNR 163, Purdue University, Cooperative Extension Service, West Lafayette.

Esteban, L.G.; Fernandez, F.G.; de Palacios, P. 2011. Prediction of plywood bonding quality using an artificial neural network. Holzforschung (65)2:209-214.

Esteves, B.; Marques, A.V.; Domingos, I.; Pereira, H. 2007. Influence of steam heating on the properties of pine (Pinus pinaster) and eucalypt (Eucalyptus globulus) wood. Wood Science and Technology 41:193-207.

Feist, W.C.; Sell, J. 1987. Weathering behavior of dimensionally stabilized wood treated by heating under pressure of nitrogen gas. Wood and Fiber Science 19(2):183-195.

Gryc, V.; Vavrčík, H.; Horáček, P. 2007. Variability in swelling of spruce (Picea abies [L.] Karst.) wood with the presence of compression wood. Journal of Forest Science 53(6):243-252.

Guler, C.; Copur, Y.; Akgul, M.; Buyuksari, U. 2007. Some chemical, physical and mechanical properties of juvenile wood from black pine (Pinus nigra Arnold) plantations. Journal of Applied Sciences 7(5):755-758. 
Gunduz, G.; Korkut, S.; Korkut, D.S. 2008. The effects of heat treatment on physical and technological properties and surface roughness of Camiyanı Black pine (Pinus nigra Arn. subsp. pallasiana var. pallasiana) wood. Bioresource Technology 99:2275-2280.

Hagan, M.T.; Demuth, H.B.; Jesus, O.D. 2002. An introduction to the use of neural networks in control systems. International Journal of Robust and Nonlinear Control 12(11): 959-985.

Haghbakhsh, R.; Adib, H.; Keshavarz, P.; Koolivand, M.; Keshtkari, S. 2013. Development of an artificial neural network model for the prediction of hydrocarbon density at high-pressure, hightemperature conditions. Thermochimica Acta 551:124-130.

Haykin, S. 1999. Neural Networks: A Comprehensive Foundation. Second Edition. Prentice Hall.

Haykin, S. 2008. Neural Computing, $2^{\text {nd }}$ ed. Prentice Hall, Princeton.

Hiziroglu, S. 2004. Dimensional changes in wood. NREM-5009, Oklahoma State University, Division of Agricultural Sciences and Natural Resources, Stillwater.

Inoue, M.; Norimoto, M.; Tanahashi, M.; Rowell, R.M. 1993. Steam or heat fixation of compressed wood. Wood and Fiber Science 25:224-235.

Kord, B.; Kialashaki, A.; Kord, B. 2010. The within-tree variation in wood density and shrinkage, and their relationship in Populus euramericana. Turkish Journal of Agriculture and Forestry 34:121126.

Korkut, S.; Budakci, M. 2010. The effects of high-temperature heat-treatment on physical properties and surface roughness of rowan (Sorbus aucuparia 1.) wood. Wood Research 55(1):67-78.

Korkut, S.; Aytin, A. 2015. Evaluation of physical and mechanical properties of Wild cherry wood heat-treated using the Thermowood process. Maderas. Ciencia y tecnología 17(1):171-178.

Lewis, C.D. 1982. International and business forecasting methods. Butterworths, London.

May, R.J.; Maier, H.R.; Dandy, G.C. 2010. Data splitting for artificial neural networks using SOM-based stratified sampling. Neural Networks 23(2):283-294.

Okan, O.T.; Deniz, I.; Tiryaki, S. 2015. Application of artificial neural networks for predicting tensile index and brightness in bleaching pulp. Maderas. Ciencia y tecnología 17(3):571-584.

Ozsahin, S. 2012. The use of an artificial neural network for modeling the moisture absorption and thickness swelling of oriented strand board. BioResources 7:1053-1067.

Ozsahin, S. 2013. Optimization of process parameters in oriented strand board manufacturing with artificial neural network analysis. European Journal of Wood and Wood Products 71:769-777.

Paul, W.; Ohlmeyer, M.; Leithoff, H. 2007. Thermal modification of OSB-strands by a onestep heat pretreatment: influence of temperature on weight loss, hygroscopicity and improved fungal resistance. Holz als Roh- und Werkstoff 65:57-63.

Rastislav, S.; Miroslav, M.; Stanislav, K.; Richard, L.; Vladimír, V. 2006. A simple method for determination of kinetics of radial, tangential and surface swelling of wood. Drvna industrija 57 (2): $75-82$.

Rojas, G.; Ortiz, O. 2010. Identification of knotty core in Pinus radiata logs from computed tomography images using artificial neural network. Maderas. Ciencia y tecnología 12(3):229-239. 
Schneid, E.; de Cademartori, P.H.G.; Gatto, D. 2014. The effect of thermal treatment on physical and mechanical properties of Luehea divaricata hardwood. Maderas. Ciencia y tecnología 16(4):413-422.

Shi, J.L.; Kocaefe, D.; Zhang, J. 2007. Mechanical behaviour of quebec wood species heattreated using thermowood process. Holz als Roh- und Werkstoff 65:255-259.

Stam, A.J. 1964. Wood and cellulose science. The Ronald Press Company, New York.

Taylor, R. 1990. Interpretation of the correlation coefficient: a basic review. Journal of Diagnostic Medical Sonography 6:35-39.

Tiryaki, S.; Malkocoglu, A.; Ozsahin, S. 2014. Using artificial neural networks for modeling surface roughness of wood in machining process. Construction and Building Materials 66:329-335.

Tiryaki, S.; Aydin, A. 2014. An artificial neural network model for predicting compression strength of heat treated woods and comparison with a multiple linear regression model. Construction and Building Materials 62:102-108.

Tiryaki, S.; Hamzacebi, C. 2014. Predicting modulus of rupture (MOR) and modulus of elasticity (MOE) of heat treated woods by artificial neural networks. Measurement 49:266-274.

TS 4083. 1983. Wood-determination of radial and tangential shrinkage. Turkish Standards Institution, Ankara.

TS 4084. 1983. Wood-determination of radial and tangential swelling. Turkish Standards Institution, Ankara.

Unsal, O.; Korkut, S.; Atik, C. 2003. The effect of heat treatment on some properties and colour in Eucalyptus (Eucalyptus camaldulensis Dehn.) wood. Maderas. Ciencia y tecnología 5(2):145-152.

Usta, I.; Guray, A. 2000. Comparison of swelling and shrinkage characteristics of Corcisan Pine (Pinus nigra var. mantima). Turkish Journal of Agriculture and Forestry 24:461-464.

Yildiz, S.; Gezer, E.D.; Yildiz, U.C. 2006. Mechanical and chemical behavior of spruce wood modified by heat. Building and Environment 41(12):1762-1766.

Zhang, D.; Sun, L.; Cao, J. 2006. Modeling of temperature-humidity for wood drying based on time-delay neural network. Journal of Forestry Research 17(2):141-144.

Zhang, G.; Ptuwo, B.E.; Hu, M.Y. 1998. Forecasting with ANN: the state of the art. International Journal of Forecasting 14:35-62. 